\title{
(C) OPEN ACCESS \\ Comparison of haemoglobin assessments by HemoCue and two automated haematology analysers in young Laotian children
}

\author{
Guy-Marino Hinnouho, ${ }^{1}$ Maxwell A Barffour, ${ }^{1}$ K Ryan Wessells, ${ }^{1}$ Kenneth H Brown, ${ }^{1,2}$ \\ Sengchanh Kounnavong, ${ }^{3}$ Bigphone Chanhthavong, ${ }^{3}$ Kethmany Ratsavong, ${ }^{3}$ \\ Chidchamai Kewcharoenwong, ${ }^{4}$ Sonja Y Hess ${ }^{1}$
}

\begin{abstract}
- Additional material is published online only. To view please visit the journal online (http://dx.doi.org/10.1136/ jclinpath-2017-204786)

'Department of Nutrition, Program in International and Community Nutrition, University of California, Davis, California, USA

${ }^{2}$ Nutrition and Global Development, Bill \& Melinda Gates Foundation, Seattle, Washington, USA ${ }^{3}$ National Institute of Public Health, Vientiane, Laos ${ }^{4}$ Faculty of Associated Medical Sciences, Centre for Research and Development of Medical Diagnostic Laboratories, Khon Kaen University, Khon Kaen, Thailand
\end{abstract}

Correspondence to Dr Guy-Marino Hinnouho, Program in International and Community Nutrition, Department of Nutrition, University of California, One Shields Avenue, Davis, CA 95616,USA; gmhinnouho@ ucdavis.edu

Received 11 September 2017 Accepted 14 November 2017 Published Online First 2 December 2017

\begin{abstract}
Background Haemoglobin ( $\mathrm{Hb}$ ) assessment by Hemocue is used widely for anaemia screening in both adults and children. However, few studies have compared the diagnostic accuracy of Hemocue with an automated haematology analyser in young children.

Aim To compare $\mathrm{Hb}$ concentrations by Hemocue $\mathrm{Hb} 301$ and two automated haematology analysers in young children in rural communities of Lao PDR.

Methods Capillary blood was collected from 6-monthold to 23-month-old children ( $n=1487)$ for determination of $\mathrm{Hb}$ concentration by Hemocue $\mathrm{Hb} 301$. On the same day, venous blood was collected for complete blood count using one of two haematology analysers (XT1800i, Sysmex, and BC-3000Plus, Mindray Medical International). In a subsample of children $(n=129)$, venous $\mathrm{Hb}$ was also measured by HemoCue $\mathrm{Hb} 301$. Agreement between the two methods was estimated using Bland-Altman plots.

Results Mean capillary Hb by Hemocue was significantly higher than mean venous $\mathrm{Hb}$ by haematology analysers combined $(108.4 \pm 10.3 \mathrm{~g} / \mathrm{L}$ vs $102.3 \pm 13.1 \mathrm{~g} / \mathrm{L} ; \mathrm{P}<0.001)$, resulting in a significantly lower anaemia prevalence $(\mathrm{Hb}<110 \mathrm{~g} / \mathrm{L})$ by Hemocue ( $53.7 \%$ vs $73.9 \% ; P<0.001)$. The Bland-Altman assessment of agreement showed a bias of $6.1 \mathrm{~g} / \mathrm{L}$ and limits of agreement were $-11.5 \mathrm{~g} / \mathrm{L}$ to $23.7 \mathrm{~g} / \mathrm{L}$. Mean venous $\mathrm{Hb}$ concentration by Hemocue $\mathrm{Hb} 301$ $(113.6 \pm 14.0 \mathrm{~g} / \mathrm{L})$ was significantly higher than mean capillary $\mathrm{Hb}$ concentration by Hemocue $\mathrm{Hb} 301$ $(110.0 \pm 10.7 ; P=0.03 \mathrm{~g} / \mathrm{L})$, which in turn was significantly higher than mean venous $\mathrm{Hb}$ concentration by the Mindray BC-3000Plus (102.3 $\pm 17.4 \mathrm{~g} / \mathrm{L})$.

Conclusion Capillary and venous $\mathrm{Hb}$ concentrations assessed by Hemocue $\mathrm{Hb} 301$ showed poor agreement compared with venous $\mathrm{Hb}$ by automated haematology analysers, resulting in significantly different anaemia prevalences.
\end{abstract}

\section{INTRODUCTION}

Anaemia is a major public health concern, affecting $43 \%$ of young children and $38 \%$ of pregnant women globally. ${ }^{1}$ Primary causes of anaemia include micronutrient deficiencies, parasitic infections, such as malaria and hookworm, and inherited haemoglobin $(\mathrm{Hb})$ disorders. ${ }^{2-5}$ Anaemia has several negative consequences on health and may cause low birth weight, preterm birth and perinatal, neonatal and maternal mortality during pregnancy. ${ }^{6}$ In addition, iron deficiency anaemia has been linked with poor psychomotor development of children and reduced physical performance in adults. ${ }^{7}$

$\mathrm{Hb}$ concentration is the most commonly used indicator of anaemia at the individual and population level ${ }^{8}$ and is used for both screening and evaluating the impact of intervention programmes. ${ }^{9}$ Numerous methods are available for measuring $\mathrm{Hb}$ concentration, ${ }^{10-14}$ of which the cyanmethemoglobin method is considered the reference method by the International Committee for Standardization in Hematology ${ }^{10}$ and is recommended by the World Health Organization (WHO). ${ }^{15}$ However, this analytical method is fairly time consuming and therefore relatively costly. ${ }^{16}$ In clinical laboratory settings, $\mathrm{Hb}$ concentration is generally assessed by automated haematology analysers, ${ }^{12}{ }^{13}$ which are very reliable and accurate, but expensive and not transportable to the field. In field settings where resources are limited, the HemoCue device has been used extensively because it is portable, easy to use and relatively inexpensive. Moreover, the HemoCue device requires only a small drop of capillary or venous blood and provides an immediate numerical $\mathrm{Hb}$ value. ${ }^{17}$

Multiple studies have examined the accuracy and precision of HemoCue results compared with automated haematology analysers in different adult populations, and findings from these studies are mixed. ${ }^{18-25}$ Several factors may explain the discrepancy between studies, including measurement errors, blood sampling site (capillary vs venous blood), ${ }^{26}$ analytical setting (laboratory vs field) and population characteristics (healthy adults, pregnant women, blood donors, ill patients, etc).

To date, few published data exist on the accuracy of HemoCue versus an automated haematology analyser in children both in laboratory ${ }^{27-29}$ and field settings. ${ }^{25}{ }^{30}$ To our knowledge, only one study included very young children. ${ }^{28}$ This study, implemented in 11-month-old to 36-month-old children in immunisation clinics in east London, found that $\mathrm{Hb}$ concentrations measured by HemoCue were consistently greater than $\mathrm{Hb}$ levels measured by a haematology analyser (Coulter counter). Because the anaemia prevalence of children under 5 years of age is assessed
Barffour MA, Wessells KR et al. J Clin Pathol

2018:71:532-538 
by HemoCue in most national surveys and considering the reported inconsistency of the relative accuracy and reliability of this method, ${ }^{717}$ the present study aimed to: (1) compare $\mathrm{Hb}$ concentrations measured by HemoCue $\mathrm{Hb} 301$ and automated haematology analysers in young children in rural communities of Lao PDR, (2) compare the estimated anaemia prevalence derived from these two methods, (3) determine the accuracy of HemoCue Hb301 using both venous and capillary blood samples compared with that of an automated haematology analyser using venous blood and (4) compare the $\mathrm{Hb}$ measurements provided by the three different project-owned HemoCue Hb301 devices.

\section{METHODS}

\section{Study population}

Data were drawn from the Lao Zinc Study, a community-based randomised controlled trial implemented in rural communities of Khammouane Province in Lao PDR (registered at www.ClinicalTrials.gov; NCT02428647). The study protocol and the consent procedure were approved by the National Ethics Committee for Health Research (Lao PDR), Institutional Review Board of the University of California, Davis (USA), and the Khon Kaen University Ethics Committee in Health Research (Thailand). Prior to any examination, written informed consent (documented by either a signature or a fingerprint in the presence of a neutral witness) was obtained from one of the child's primary caregivers (mother, father or legal guardian). In a first set of analyses of the present paper, we used data from a convenience subsample of 1487 children, 6-23 months of age at baseline whose $\mathrm{Hb}$ concentrations were assessed during study enrolment (September 2015 through August 2016; objectives 1 and 2). All data available were used for the present methodological comparison, which was considered adequate based on sample size recommendations for the Bland-Altman method by Lu et al. ${ }^{31}$ Retrospective sample size calculation showed that our sample size of $n=1487$ allowed us to estimate the bias with a $95 \% \mathrm{CI}$ of $0.91 \mathrm{~g} / \mathrm{L}$ and the Bland-Altman limits of agreement with a $95 \%$ CI of $1.6 \mathrm{~g} / \mathrm{L}$. For logistical reasons, the venous blood samples were analysed by two different haematology analysers, as described in more detail below. In a second set of analyses involving 129 children, 15-32 months of age, we compared venous and capillary $\mathrm{Hb}$ concentrations measured during the endline assessment (January through March 2017; objective 3). In a third set of analyses involving 29 children, 15-32 months of age, we compared the $\mathrm{Hb}$ measurements by each of the three project-owned HemoCue Hb301 devices (November 2016; objective 4).

\section{Estimation of $\mathrm{Hb}$ concentration}

Non-fasting capillary and venous blood samples were collected within a few minutes of each other by trained phlebotomists, with the child in a seated position. Blood was drawn from the left side of the body whenever possible, and the sampling sites were cleaned with alcohol and left to air dry for a few seconds.

For capillary blood collection, the tip of the left middle finger was pricked with a lancet (Haemolancet Plus, HTL-STREFA, Poland), and the first drop of blood was wiped away with cotton. The fingertip of the left middle finger was used whenever possible because previous studies have reported a large within-subject variation in $\mathrm{Hb}$ concentration from the left to the right hand. ${ }^{9}$ A standard $\mathrm{Hb} 301$ microcuvette was used to collect the second drop of blood, and the cuvette was then wiped on the sides to remove any excess blood and immediately inserted into the HemoCue Hb301 device (HemoCue $\mathrm{AB}$, Angelholm, Sweden) for analysis. The HemoCue Hb301 system determines the $\mathrm{Hb}$ concentration by measuring the absorbance of whole blood at an $\mathrm{Hb} / \mathrm{HbO} 2$ isosbestic point. The device uses a double wavelength measuring method, $506 \mathrm{~nm}$ and $880 \mathrm{~nm}$, for compensation of turbidity. ${ }^{32}$ The results are displayed numerically in $\mathrm{g} / \mathrm{dL}$ at the time of the measurement. In the present study, $\mathrm{Hb}$ results were recorded on an electronic device and manually in a notebook.

Venous blood was drawn from an antecubital, dorsal metacarpal or great saphenous vein into an EDTA tube (S-Monovette (K3 EDTA), Sarstedt AG \& Co, Nümbrecht, Germany) from children who were not acutely ill with fever or reported diarrhoea. Right after collection, the tube was gently inverted $8-10$ times and placed into a cold box at $4^{\circ} \mathrm{C}-8^{\circ} \mathrm{C}$. The sample was transported the same day either to Nakhon Phanom Hospital, Thailand, or to the project field laboratory in Nongbok, Lao PDR. A complete blood count (CBC) was performed to estimate $\mathrm{Hb}$ concentrations using one of two automated haematology analysers: XT- $1800 \mathrm{i}$ by Sysmex $(\mathrm{n}=633$; at the Nakhon Phanom Hospital, Thailand) or BC-3000Plus by Mindray Medical International Ltd ( $\mathrm{n}=854$; at the project field laboratory, Nongbok, Lao PDR) for different aspects of the Lao Zinc Study. Using a unique diode laser bench, the Sysmex XT-1800i fluorescent flow cytometry uses a cyanide-free, sodium lauryl sulfate method and provides the sensitivity needed for measuring and differentiating cell types in whole blood and body fluid samples. Using a cyanidefree reagent, the BC-3000Plus uses a colorimetric method to determine $\mathrm{Hb}$ concentrations. $\mathrm{Hb}$ measurements with the HemoCue Hb301 and the two automated haematology analysers were performed in accordance with the manufacturers' operating manual.

For objective 3, venous $\mathrm{Hb}$ was measured using the HemoCue Hb301 device in a subsample of children to explore the differences between venous and capillary $\mathrm{Hb}$ concentrations by the HemoCue Hb301 device. After gently inverting the EDTA tube 8-10 times, approximately $50 \mu 1$ of whole blood was pipetted and placed on a microscopic slide. The blood drop was subsequently aspirated into a standard $\mathrm{Hb} 301$ microcuvette and immediately inserted into the HemoCue $\mathrm{Hb} 301$ device to determine the venous $\mathrm{Hb}$ concentration.

To compare the $\mathrm{Hb}$ measurements provided by the different project-owned HemoCue Hb301 devices (objective 4), venous $\mathrm{Hb}$ was measured in a subsample of children $(\mathrm{n}=29)$, using three different devices. For each measurement, approximately $50 \mu \mathrm{l}$ of whole venous blood collected in an EDTA tube was placed on a microscopic slide and aspirated into a standard Hb301 microcuvette. A new blood drop was placed on a new microscopic slide for each HemoCue device.

Of the three different HemoCue Hb301 devices, the HemoCue $\mathrm{Hb} 301 \# 1$ and \#2 were used in the field for routine capillary $\mathrm{Hb}$ concentration determinations for the main trial (objectives 1 and 2). HemoCue Hb301 \#1 was used in the substudy of the 129 children (objective 3). HemoCue Hb301 \#3 was a back-up device, kept in the laboratory and was only used for the HemoCue comparison substudy (objective 4).

\section{Quality control}

Quality control checks were performed weekly for the HemoCue Hb301 devices (quality control checks for HemoCue Hb301 \#3 were performed weekly only when the substudy 
was implemented), weekly for the project-owned BC-3000Plus haematology analyser and daily for the XT-1800i haematology analyser by Sysmex at the Nakhon Phanom Hospital using the CBC-3D haematology control and a commercial control sample from Meditop Company, respectively. For external quality control, the hospital-based haematology analyser was also qualified by the External Quality Assessment Schemes in Clinical Microscopy from the Faculty of Medical Technology, Mahidol University, and by the Bureau of Laboratory Quality Standards, Ministry of Public Health, Thailand.

The Eurotrol Hb301 Control (levels 1 and 2) was used to verify the precision and accuracy of the HemoCue Hb301 devices. The expected $\mathrm{Hb}$ values provided by the manufacturer were $71.0 \pm 8.0$ and $130.0 \pm 12.0 \mathrm{~g} / \mathrm{L}$ for levels 1 and 2, respectively.

\section{Statistical analysis}

Data are presented as mean $\pm S D$ or percentage when appropriate. Results of the automated haematology analysers were analysed combined and individually, as described in more detail below. Paired t-tests and McNemar tests were used to compare the difference between mean $\mathrm{Hb}$ concentrations and the anaemia prevalences, respectively, between the different methods of assessment. Analysis of variance followed by Bonferroni corrected post hoc pairwise tests was used to compare the average bias between age groups. The correlation between the HemoCue Hb301 and the automated haematology analysers was plotted graphically to assess a possible linear association between the $\mathrm{Hb}$ values estimated by the two methods, ${ }^{33}$ and the Pearson's correlation coefficient $\left(r_{p}\right)$ was calculated.

The prevalence of anaemia was determined using the $\mathrm{Hb}$ cut-off for children $6-59$ months of age $(\mathrm{Hb}<110 \mathrm{~g} / \mathrm{L}) .{ }^{8}$ The automated haematology analysers were considered the reference method against which the sensitivity and specificity of the HemoCue Hb301 were determined.

The concordance correlation coefficient $(\rho c)$ or Lin's coefficient, ${ }^{34}$ which combines measures of both precision and accuracy, was used to determine whether the observed data significantly deviated from the line of perfect concordance (ie, the line at 45 degrees). The bias and limits of agreement between the HemoCue Hb301 and the automated haematology analysers were estimated using Bland-Altman plots. ${ }^{35}$

Several complementary analyses were undertaken to assess the robustness of our findings. First, we repeated the same analyses with each automated analyser individually to assess

Table 1 Haemoglobin concentration and anaemia prevalence in young Laotian children $(n=1487)$ using two different methods of assessment

\begin{tabular}{llll}
\hline & $\begin{array}{l}\text { Hemocue } \\
\text { Hb301 }\end{array}$ & $\begin{array}{l}\text { Automated } \\
\text { haematology } \\
\text { analysers combined* }\end{array}$ P value \\
\hline $\begin{array}{l}\text { Haemoglobin concentration, g/L } \\
\text { Mean } \pm \text { SD }\end{array}$ & $108.4 \pm 10.3$ & $102.3 \pm 13.1$ & $<0.0001$ \\
Range & $70-141$ & $34-178$ & \\
SE & 0.3 & 0.3 & $<0.0001$ \\
Anaemia prevalence, $\mathrm{n}(\%)$ & $799(53.7)$ & $1099(73.9)$ \\
Sensitivity of Hemocue Hb301 (\%) & 68.7 & Ref \\
Specificity of Hemocue Hb301 (\%) & 85.8 & Ref \\
$\begin{array}{l}\text { Agreement of the two methods } \\
(\%)\end{array}$ & & 71.9 \\
\hline
\end{tabular}

*XT-1800i by Sysmex and BC-3000Plus by Mindray Medical International. the accuracy of the HemoCue Hb301 device against each automated analyser. It is important to note that, for this analysis, each comparison was done in a different subgroup of children. Second, we repeated the main analyses by age group (6-11, 12-17 and 18-24 months) to explore whether the accuracy of the HemoCue Hb301 device differed by age group. Third, in a subsample of 129 children, we measured both venous $\mathrm{Hb}$ and capillary $\mathrm{Hb}$ using the HemoCue $\mathrm{Hb} 301$ and venous $\mathrm{Hb}$ using the automated haematology analyser at the field site (Mindray BC-3000Plus). Finally, we compared the $\mathrm{Hb}$ measurements provided by the different project owned HemoCue Hb301 devices using venous blood of 29 children.

Analyses were undertaken using Stata 14 (StataCorp 2015, College Station, Texas, USA). Reported P values are two-tailed, and $\mathrm{P}$ values $<0.05$ were considered to be statistically significant.

\section{RESULTS}

Capillary $\mathrm{Hb}$ concentration by HemoCue $\mathrm{Hb} 301$ versus venous $\mathrm{Hb}$ concentration by two automated analysers combined

A total of 1487 children were included in this set of analyses. Their mean age \pm SD was $14.7 \pm 5.1$ months, and $48.7 \%$ were female. Of these children, $35.2 \%(n=523)$ were $6-11$ months, $33.8 \%(n=502)$ were $12-17$ months and $31.1 \%(n=462)$ were 18-24 months.

The mean capillary $\mathrm{Hb}$ value obtained by HemoCue $\mathrm{Hb} 301$ was significantly greater than the mean venous $\mathrm{Hb}$ value obtained by the two automated haematology analysers combined $(108.4 \pm 10.3 \mathrm{~g} / \mathrm{L}$ vs $102.3 \pm 13.1 \mathrm{~g} / \mathrm{L} ; \quad \mathrm{P}<0.001$; table 1). Accordingly, the prevalence of anaemia in the study population was significantly lower using the HemoCue Hb301 device than the automated haematology analysers combined (53.7\% vs $73.9 \% ; \mathrm{P}<0.001)$.

The sensitivity and specificity of the HemoCue Hb301 compared with the two automated haematology analysers combined were $68.7 \%$ and $85.8 \%$, respectively, suggesting that the two methods agreed better in non-anaemic children (table 1). The two methods agreed in $71.9 \%$ of cases. A linear regression showed a strong correlation between the two methods (correlation coefficient $r_{p}=0.73 ; P<0.001$ ). The concordance correlation coefficient was $\rho c=0.63(\mathrm{P}<0.001)$ and the reduced major axis and the line of perfect concordance were not aligned (figure 1). Compared with venous $\mathrm{Hb}$ concentrations measured by the two automated haematology analysers, the HemoCue $\mathrm{Hb} 301$ device appears to overestimate capillary $\mathrm{Hb}$ concentrations at lower $\mathrm{Hb}$ levels. The Bland-Altman plot revealed an overall bias of $6.1 \mathrm{~g} / \mathrm{L}$ and the limits of agreement (from -11.5 to $23.7 \mathrm{~g} / \mathrm{L}$ ) indicated that the two methods did not have good agreement (figure 2).

Results of analyses with the automated haematology analysers considered individually showed similar trends (online supplementary table S1 and figures S1 and S2). Mean capillary $\mathrm{Hb}$ by Hemocue Hb301 was significantly higher than mean $\mathrm{Hb}$ obtained by both the Sysmex XT-1800 (110.7 $\pm 9.7 \mathrm{~g} / \mathrm{L}$ vs107.4 $\pm 12.5 \mathrm{~g} / \mathrm{L} ; \mathrm{P}<0.001)$ and the Mindray BC-3000Plus $(106.7 \pm 10.4 \mathrm{~g} / \mathrm{L}$ vs $98.4 \pm 12.2 \mathrm{~g} / \mathrm{L} ; \quad \mathrm{P}<0.001)$. Sensitivity, specificity and agreement of Hemocue Hb301 were slightly better with the Sysmex XT-1800i haematology analyser.

The mean capillary $\mathrm{Hb}$ obtained by HemoCue Hb301 was significantly greater than the mean venous $\mathrm{Hb}$ obtained by the two automated haematology analysers combined in all three age groups (all $\mathrm{P}<0.0001)$, but the difference between methods was similar in 12-month to 17 -month and 18-month to 24 -month children $(5.9 \mathrm{~g} / \mathrm{L} \quad$ vs5.0 $\mathrm{g} / \mathrm{L} ; \quad \mathrm{P}=0.33)$, but 


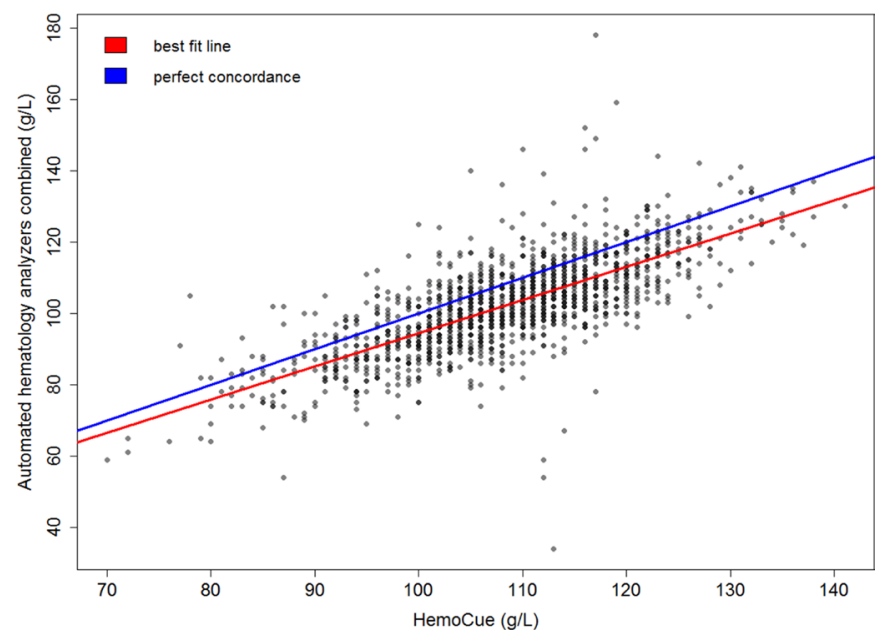

Figure 1 Correlation of $\mathrm{Hb}$ concentrations assessed by Hemocue Hb301 and automated analysers combined (XT-1800i by Sysmex and BC-3000Plus by Mindray Medical International Ltd.) and concordance plots between the 2 methods.

significantly lower than that of children 6-11 months of age $(5.9 \mathrm{~g} / \mathrm{L}$ vs $7.3 \mathrm{~g} / \mathrm{L} ; \mathrm{P}=0.036$ and $5.0 \mathrm{~g} / \mathrm{L}$ vs $7.3 \mathrm{~g} / \mathrm{L}: \mathrm{P}<0.003$, respectively) (online supplementary table S2). Regardless of the age group, the box plots comparing the distribution of $\mathrm{Hb}$ levels by age group using the two methods (online supplementary figure S3) show a narrower range with HemoCue Hb301 compared with those with automated haematology analysers combined.

\section{$\mathrm{Hb}$ concentration in capillary and venous blood by HemoCue Hb301 versus venous blood by Mindray BC-3000Plus}

Mean venous $\mathrm{Hb}$ concentration by Hemocue Hb301 was significantly higher than mean capillary $\mathrm{Hb}$ concentration by Hemocue Hb301, which in turn was significantly higher than mean venous $\mathrm{Hb}$ concentration by the Mindray BC-3000Plus $(113.6 \pm 14.0,111.7 \pm 10.7$ and $102.3 \pm 17.4 \mathrm{~g} / \mathrm{L}$, respectively; all $\mathrm{P}<0.05, \mathrm{n}=129$; table 2 ). However, it has to be noted that the difference between mean venous and capillary $\mathrm{Hb}$ concentration by Hemocue $\mathrm{Hb} 301$ was small but clinically significant.

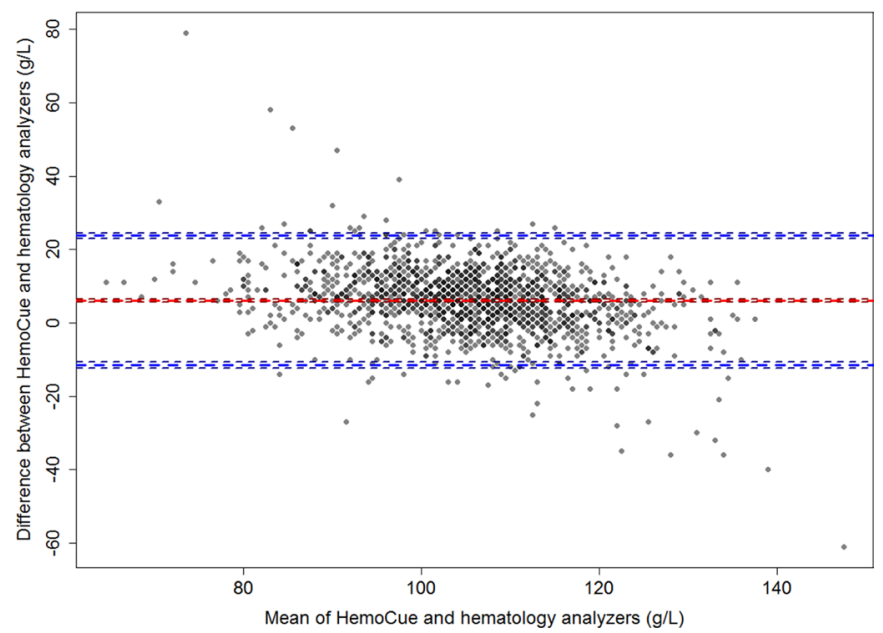

Figure 2 Bland-Altman plot showing agreement in haemoglobin concentration of young Laotian children assessed by HemoCue $\mathrm{Hb} 301$ and two automated haematology analysers combined (XT-1800i by Sysmex and BC-3000Plus by Mindray Medical International).
Table 2 Paired comparisons of haemoglobin concentrations by HemoCue Hb301 (capillary and venous) and by Mindray BC-3000Plus in young Laotian children $(n=129)$

\begin{tabular}{|c|c|c|c|c|c|}
\hline Comparisons & $\begin{array}{l}\mathrm{Hb} \\
(\mathrm{mean} \pm \mathrm{SD}), \\
\mathrm{g} / \mathrm{L}\end{array}$ & $P^{*}$ & $\begin{array}{l}\text { Bias (limits of } \\
\text { agreement) }\end{array}$ & $\begin{array}{l}\text { Anaemia } \\
\text { prevalence } \\
\mathrm{n}(\%)\end{array}$ & $\mathrm{Pt}$ \\
\hline $\begin{array}{l}\text { Capillary } \\
\text { HemoCue }\end{array}$ & $111.0 \pm 10.7$ & & & $54(41.9)$ & \\
\hline versus & & 0.03 & $\begin{array}{l}-2.5 \\
(-4.8 \text { to }-0.2)\end{array}$ & & 0.21 \\
\hline Venous HemoCue & $113.6 \pm 14.0$ & & & $47(36.4)$ & \\
\hline $\begin{array}{l}\text { Capillary } \\
\text { HemoCue }\end{array}$ & $111.0 \pm 10.7$ & & & $54(41.9)$ & \\
\hline versus & & $<0.0001$ & $\begin{array}{l}8.7 \\
\text { (6.0 to } 11.4 \text { ) }\end{array}$ & & $<0.0001$ \\
\hline $\begin{array}{l}\text { Venous automated } \\
\text { analyser }\end{array}$ & $102.3 \pm 17.4$ & & & $85(65.9)$ & \\
\hline Venous HemoCue & $113.6 \pm 14.0$ & & & $47(36.4)$ & \\
\hline versus & & $<0.0001$ & $\begin{array}{l}11.2 \\
\text { (8.2 to } 14.2 \text { ) }\end{array}$ & & $<0.0001$ \\
\hline $\begin{array}{l}\text { Venous automated } \\
\text { analyser }\end{array}$ & $102.3 \pm 17.4$ & & & $85(65.9)$ & \\
\hline
\end{tabular}

${ }^{*} \mathrm{P}$ value for difference of mean $\mathrm{Hb}$ concentration.

†P value for anaemia prevalence.

$\mathrm{Hb}$, haemoglobin.

The prevalence of anaemia was $36.4 \%, 41.9 \%$ and $65.9 \%$, respectively, in venous blood by Hemocue Hb301, capillary blood by Hemocue Hb301 and venous blood by automated analyser.

\section{$\mathrm{Hb}$ measurements provided by the three different HemoCue Hb301 devices}

In the analyses comparing the results of the three different HemoCue Hb301 devices for 29 venous blood samples (online supplementary table $\mathrm{S} 3$ ), mean $\mathrm{Hb}$ did not differ significantly between HemoCue Hb301 \#1 and \#2 used in the field $(112.9 \pm 8.8 \mathrm{~g} / \mathrm{L}$ vs $113.2 \pm 6.9 \mathrm{~g} / \mathrm{L} ; \mathrm{P}=0.96)$. However, mean $\mathrm{Hb}$ concentration obtained with HemoCue Hb 301 \#3 $(117.1 \pm 9.4 \mathrm{~g} / \mathrm{L})$ was significantly higher than the mean $\mathrm{Hb}$ obtained with both HemoCue Hb301 \#1 and \#2. There was a good correlation among the three different HemoCue Hb301 devices ( $r$ ranged from 0.62 to 0.89 ). However, based on the Bland-Altman plots, the agreement was good only between the HemoCue Hb301 \#1 and \#2 with a bias (95\% limits of agreement) of $-0.28(-8.23$ to 7.68$) \mathrm{g} / \mathrm{L}$. We found a within-instrument variation (coefficient of variation $(\mathrm{CV})$ ) of $7.7 \%$, 6.1\% and 8.0\%, respectively, for HemoCue \#1, \#2 and \#3.

\section{Quality control results}

Results from the quality control tests using Eurotrol HB301 control solutions showed that the average concentration was $74.0 \pm 3.0 \mathrm{~g} / \mathrm{L}(\mathrm{CV}=3.8 \%)$ and $131.0 \pm 3.0 \mathrm{~g} / \mathrm{L}(\mathrm{CV}=2.5 \%)$ for levels 1 and 2, respectively, which was within the acceptable range suggested by the manufacturer.

\section{DISCUSSION}

In this study of almost 1500 young children, mean capillary $\mathrm{Hb}$ concentrations by HemoCue Hb301 were significantly higher compared with mean venous $\mathrm{Hb}$ concentrations determined by two automated haematology analysers (Sysmex XT-1800i and Mindray BC-3000Plus), resulting in a significantly lower anaemia prevalence by Hemocue $(53.7 \%$ vs $73.9 \%)$. Possible 
reasons for this difference are true physiological differences in $\mathrm{Hb}$ concentrations of venous versus capillary blood, differences in accuracy of the analytical instruments and differences in specimen collection and processing prior to analyses. To investigate whether this difference was due to the blood sampling site or the analytical instrument used, we also assessed capillary and venous $\mathrm{Hb}$ by HemoCue $\mathrm{Hb} 301$ and compared these with venous $\mathrm{Hb}$ concentration by the Mindray BC-3000Plus in a substudy of 129 children and found that venous $\mathrm{Hb}$ levels were slightly higher than capillary $\mathrm{Hb}$ concentrations by HemoCue $\mathrm{Hb} 301$ and that both were substantially higher than venous $\mathrm{Hb}$ concentrations obtained with the Mindray BC-3000Plus automated haematology analyser, resulting in a significantly lower prevalence of anaemia when the HemoCue Hb301 device was used. Thus, regardless of the type of blood sample, HemoCue Hb301 showed a bias towards higher $\mathrm{Hb}$ concentrations compared with an automated haematology analyser.

The instruments used in our study performed well in quality control testing throughout the project. Moreover, the two HemoCue Hb301 devices (\#1 and \#2) used in the main analyses yielded similar results and the third device (\#3) with significantly higher $\mathrm{Hb}$ concentrations was not used in any of the comparisons other than the device comparison for the present report. Thus, we trust that our findings derive from accurate and precise instruments. However, it has to be noted that the quality control solutions for Hemocue devises provided by Eurotrol (Burlington, Massachusetts, USA) consider a very wide range acceptable, thus not allowing to properly assess accuracy and precision of Hemocue devices. A reduction in acceptable range along with the possibility to adjust the Hemocue device should be reconsidered for future product developments of the Hemocue devices.

In contrast to our study, which found that venous Hb levels were slightly higher than capillary $\mathrm{Hb}$ concentrations using HemoCue Hb301, some previous studies have reported that capillary $\mathrm{Hb}$ by HemoCue was higher than venous $\mathrm{Hb}$ concentrations by HemoCue. ${ }^{26} 36$ The difference in $\mathrm{Hb}$ concentrations between capillary and venous blood samples has been explained by the fact that a capillary blood drop reflects the content of blood from various loop capillaries and small arterioles and venules, and a venous sample reflects the blood coursing through the veins, heart and arteries. ${ }^{26}$ A high within-subject variability (biological variability) of capillary blood samples compared with venous blood has previously been documented. ${ }^{37}$ However, our study does not fully support this hypothesis because we also found that venous $\mathrm{Hb}$ levels determined by HemoCue Hb301 were higher than venous $\mathrm{Hb}$ concentrations determined by an automated haematology analyser, implying that the primary difference found in our study was due to the analytical method used. Nevertheless, we found a small but significant difference between capillary and venous $\mathrm{Hb}$ concentrations by HemoCue Hb301, which may be due to improper capillary sampling such as excessive finger squeezing or partial filling of the microcuvette. ${ }^{17}$

Our finding that capillary $\mathrm{Hb}$ concentrations by HemoCue $\mathrm{Hb} 301$ are significantly higher than venous $\mathrm{Hb}$ concentrations obtained with two different automated haematology analysers is consistent with some previous studies in pregnant women in Sudan ${ }^{19}$ and Brazil, ${ }^{36}$ blood donors in the USA ${ }^{26}$ and different population subgroups (preschool children, school children, pregnant women, non-pregnant women and men) in Ghana, ${ }^{25}$ but not with studies in women with genetic $\mathrm{Hb}$ disorders in Cambodia, ${ }^{21}$ adults and children in Mexico, ${ }^{29}$ blood donors in Ireland ${ }^{38}$ and children in South Africa. ${ }^{30}$ Time and position during blood collection ${ }^{39} 40$ have been suggested to explain discrepancies between different devices and to influence the variability in $\mathrm{Hb}$ levels obtained by HemoCue. An additional source of error may be inadequate mixing of venous blood in the blood collection tube, which may lead to a reading of relatively more plasma rather than red blood cells by the automated analyser and would result in a lower $\mathrm{Hb}$ concentration. However, this may be less likely in our study since we found consistent results with automated haematology analysers run by different technicians based in two independent laboratories. To minimise technical errors we emphasised the correct blood collection and processing for each analytical method during training and continued supervision.

Direct comparison of our findings with previous studies is complicated by several factors. First, we used the HemoCue $\mathrm{Hb} 301$, while other studies used either the HemoCue B-Hemoglobin or HemoCue Hb201, which employs different biochemical methods to determine $\mathrm{Hb}$ concentrations. In addition, we used Sysmex XT-1800i and Mindray BC-3000Plus automated analysers, whereas others used other instruments. Other factors that differ across studies are the study settings, the participants' age range and ethnicity and whether $\mathrm{Hb}$ was assessed on fasting or non-fasting blood. ${ }^{41}$ Our study included very young children (age ranged from 6 to 32 months old), while other studies included older children (1-4 years old ${ }^{25}$ or 6-8 years old ${ }^{30}$ ) and found HemoCue to be comparable with the Sysmex KX21N and the Siemens Advia 2120 analysers, respectively. Indeed, our results suggest that the age of the study population and the anaemia prevalence are potentially important factors. Specifically, we found that the bias (difference between mean $\mathrm{Hb}$ concentrations using the two methods) is similar in 12-month to 17 -month and 18-month to 24-month children, but significantly lower than that of children 6-11 months of age; potential explanations of this finding may be that the anaemia prevalence was higher in younger children or that blood collection may be more challenging among very young children. Another factor complicating the comparison with other studies is represented by the range of $\mathrm{Hb}$ concentrations in the study population. In a study of over 36000 paired capillary and venous samples of adult blood donors, venous $\mathrm{Hb}$ levels by automated haematology analyser were consistently higher than capillary levels by HemoCue when the $\mathrm{Hb}$ concentrations were in the lower part of the normal non-anaemic range. ${ }^{38}$ Similarly, a study in Cambodian women with genetic $\mathrm{Hb}$ disorders reported that the HemoCue (HemoCue Hb 201+Hemocue AB) appears to underestimate $\mathrm{Hb}$ concentrations in capillary blood as compared with venous $\mathrm{Hb}$ by Sysmex at lower $\mathrm{Hb}$ concentrations and to overestimate $\mathrm{Hb}$ concentrations at higher $\mathrm{Hb}$ concentrations, resulting in false positives in the diagnosis of anaemia. ${ }^{21}$ This is in contrast to our study, which found that HemoCue $\mathrm{Hb} 301$ overestimated capillary $\mathrm{Hb}$ levels at lower $\mathrm{Hb}$ concentrations, resulting in a lower prevalence of anaemia.

As mentioned above, the two HemoCue Hb301 devices used in the field during enrolment and endline assessments provided comparable results, while a third back-up device yielded significantly different concentrations. Similarly, inconsistent measurements were found using 12 different HemoCue Hb301 devices in a methodological study of women in Cambodia. ${ }^{42}$ Further investigation is needed to determine inherent variability among different HemoCue Hb301 devices, and results should be routinely compared when multiples devices are deployed in a single study. 
One strength of this study is its large sample size, which allowed us to explore the agreement between methods by age group. In addition, we ran different sets of analyses to compare capillary and venous $\mathrm{Hb}$ using HemoCue Hb301, and we included regular quality control and a methodological comparison of three individual HemoCue Hb301 devices owned by the project. Moreover, the capillary and venous blood draws occurred within a few minutes of each other for each child. This study also has some limitations. It has been suggested that the HemoCue device may be more accurate in $\mathrm{Hb}$ concentration determination than automated analysers $^{43}$ given that the latter requires a sample dilution, while HemoCue assesses $\mathrm{Hb}$ directly and is not affected by changes in turbidity. We were not able to confirm this statement as we did not assess $\mathrm{Hb}$ concentrations using the cyanmethemoglobin method, which is considered the reference procedure by the International Committee for Standardization in Hematology and WHO. ${ }^{10}$ We were also not able to compare the accuracy of the two automated haematology analysers against each other in the same sample of children because the respective subsamples were collected for different aspects of the Lao Zinc Study. It is worth mentioning that a WHO consultation on $\mathrm{Hb}$ assessment is ongoing and will likely shed new light on guidelines and recommendations for $\mathrm{Hb}$ assessment and interpretation.

\section{CONCLUSION}

To date, our study is the largest study comparing capillary $\mathrm{Hb}$ concentration assessed by HemoCue $\mathrm{Hb} 301$ with venous $\mathrm{Hb}$ concentrations determined by automated analysers in young children. Regardless of the type of blood sample, the HemoCue device showed poor agreement compared with two automated haematology analysers, resulting in significantly different anaemia prevalences. The HemoCue is useful in many different settings and remains a widely used method in field settings as it has several advantages and is relatively inexpensive compared with automated haematology analysers. However, given the difference in anaemia prevalences found with the different methods, further research is needed to better understand potential sources of error in the $\mathrm{Hb}$ assessment by HemoCue with the aim to better train phlebotomists and implement appropriate standardised procedures.

\section{Take home messages}

The Hemocue Hb301 device showed poor agreement compared with two automated haematology analysers.

- Capillary haemoglobin $(\mathrm{Hb})$ concentration by Hemocue Hb301 was higher than venous $\mathrm{Hb}$ concentration by automated haematology analyser.

- Venous $\mathrm{Hb}$ concentration by Hemocue $\mathrm{Hb} 301$ was higher than capillary $\mathrm{Hb}$ concentration by Hemocue $\mathrm{Hb} 301$.

- Methodological differences resulted in a significantly lower anaemia prevalence by Hemocue.

\section{Handling editor Mary Frances McMullin.}

Acknowledgements We thank the entire Lao Zinc Study team and Charles D Arnold (University of California Davis, USA) for his review of the statistical analyses. In addition, we sincerely thank all of the participating children and their parents, the local communities and health districts of the Khammouane Province, Lao PDR.

Contributors SYH was responsible of the design of the study. G-MH, MAB, KRW, SK, BC, KR and SYH supervised data collection. CK coordinated the complete blood count analyses with the Sysmex XT-1800i haematology analyser.
G-MH completed the statistical analyses and drafted the manuscript. MAB, KRW, KHB and SYH edited the manuscript. All authors reviewed and approved the final manuscript.

Funding Funding for this research was provided by the Mathile Institute for the Advancement of Human Nutrition, Nutrition International (formerly known as the Micronutrient Initiative) and the Bill \& Melinda Gates Foundation.

Competing interests KHB works for the Bill \& Melinda Gates Foundation. The spouse of SYH works for the Bill \& Melinda Gates Foundation. All other authors have no competing interests to declare.

Ethics approval National Ethics Committee for Health Research (Lao PDR), Institutional Review Board of the University of California, Davis (USA), and the Khon Kaen University Ethics Committee in Health Research (Thailand).

Provenance and peer review Not commissioned; externally peer reviewed.

Open Access This is an Open Access article distributed in accordance with the terms of the Creative Commons Attribution (CC BY 4.0) license, which permits others to distribute, remix, adapt and build upon this work, for commercial use, provided the original work is properly cited. See: http://creativecommons.org/licenses/by/4.0/

(c) Article author(s) (or their employer(s) unless otherwise stated in the text of the article) 2018. All rights reserved. No commercial use is permitted unless otherwise expressly granted.

\section{REFERENCES}

1 Stevens GA, Finucane MM, De-Regil LM, et al. Global, regional, and national trends in haemoglobin concentration and prevalence of total and severe anaemia in children and pregnant and non-pregnant women for 1995-2011: a systematic analysis of population-representative data. Lancet Glob Health 2013;1:e16-25.

2 Black RE, Victora CG, Walker SP, et al. Maternal and child undernutrition and overweight in low-income and middle-income countries. Lancet 2013;382:427-51.

3 Balarajan Y, Ramakrishnan U, Ozaltin E, et al. Anaemia in low-income and middleincome countries. Lancet 2011;378:2123-35.

4 Desai M, ter Kuile FO, Nosten F, et al. Epidemiology and burden of malaria in pregnancy. Lancet Infect Dis 2007;7:93-104.

5 Brooker S, Hotez PJ, Bundy DA. Hookworm-related anaemia among pregnant women: a systematic review. PLoS Negl Trop Dis 2008;2:e291.

6 Haider BA, Olofin I, Wang M, et al. Anaemia, prenatal iron use, and risk of adverse pregnancy outcomes: systematic review and meta-analysis. BMJ 2013;346:\{3443.

7 WHO. Iron deficiency anemia: assessment, prevention, and control. Geneva: WHO, 2001.

8 WHO. Haemoglobin concentrations for the diagnosis of anaemia and assessment of severity. vitamin and mineral nutrition information system. Geneva, 2011.

9 Morris SS, Ruel MT, Cohen RJ, et al. Precision, accuracy, and reliability of hemoglobin assessment with use of capillary blood. Am J Clin Nutr 1999;69:1243-8.

10 van Assendelft OW, Horton BR, Parvin RM. Calibration and control in haemoglobinometry. Clin Lab Haematol 1990;12(Suppl 1):31-42.

11 Bridges NPR, Van Assendelft OW. Evaluation of a new system for hemoglobin measurement. Am Clin Products Rev 1987:6:22-5.

12 De Rosa SC, Roederer M, cytometry E-colorflow. A powerful tool for elucidation of the complex immune system. Clin Lab Med 2001;21:697-712.

13 Lau AY, Lee LP, Chan JW. An integrated optofluidic platform for Raman-activated cell sorting. Lab Chip 2008;8:1116-20.

14 Stott GJ, Lewis SM. A simple and reliable method for estimating haemoglobin. Bull World Health Organ 1995;73:369-73.

15 Ranganathan H, Gunasekaran N. Simple method for estimation of hemoglobin in human blood using color analysis. IEEE Trans Inf Technol Biomed 2006;10:657-62.

16 Sari M, de Pee S, Martini E, et al. Estimating the prevalence of anaemia: a comparison of three methods. Bull World Health Organ 2001;79:506-11.

17 Sharman A. Anemia testing in population-based surveys: general information and guidelines for country monitors and program managers. Calverton, Maryland USA: ORC Macro, 2000.

18 Mimoz O, Frasca D, Médard A, et al. Reliability of the HemoCue ${ }^{\circledR}$ hemoglobinometer in critically ill patients: a prospective observational study. Minerva Anestesiol 2011;77:979-85.

19 Adam I, Ahmed S, Mahmoud MH, et al. Comparison of HemoCue ${ }^{\circledR}$ hemoglobinmeter and automated hematology analyzer in measurement of hemoglobin levels in pregnant women at Khartoum hospital, Sudan. Diagn Pathol 2012;7:30.

20 Rudolf-Oliveira RC, Gonçalves KT, Martignago ML, et al. Comparison between two portable hemoglobinometers and a reference method to verify the reliability of screening in blood donors. Transfus Apher Sci 2013:49:578-82.

21 Karakochuk CD, Janmohamed A, Whitfield KC, et al. Evaluation of two methods to measure hemoglobin concentration among women with genetic hemoglobin disorders in Cambodia: a method-comparison study. Clin Chim Acta 2015;441:148-55.

22 Lamhaut L, Apriotesei R, Combes $\mathrm{X}$, et al. Comparison of the accuracy of noninvasive hemoglobin monitoring by spectrophotometry $(\mathrm{SpHb})$ and HemoCue® with automated laboratory hemoglobin measurement. Anesthesiology 2011;115:548-54. 
23 Chen PP, Short TG, Leung DH, et al. A clinical evaluation of the Hemocue haemoglobinometer using capillary, venous and arterial samples. Anaesth Intensive Care 1992;20:497-500.

24 Rippmann CE, Nett PC, Popovic D, et al. Hemocue, an accurate bedside method of hemoglobin measurement? J Clin Monit 1997;13:373-7.

25 Nkrumah B, Nguah SB, Sarpong N, et al. Hemoglobin estimation by the HemoCue® portable hemoglobin photometer in a resource poor setting. BMC Clin Pathol 2011;11:5.

26 Patel AJ, Wesley R, Leitman SF, et al. Capillary versus venous haemoglobin determination in the assessment of healthy blood donors. Vox Sang 2013;104:317-23.

27 Cohen AR, Seidl-Friedman J. HemoCue system for hemoglobin measurement. Evaluation in anemic and nonanemic children. Am J Clin Pathol 1988;90:302-5.

28 Mills AF, Meadows N. Screening for anaemia: evaluation of a haemoglobinometer. Arch Dis Child 1989;64:1468-71.

29 Neufeld L, García-Guerra A, Sánchez-Francia D, et al. Hemoglobin measured by Hemocue and a reference method in venous and capillary blood: a validation study. Salud Publica Mex 2002:44:219-27.

30 Gwetu TP, Chhagan MK. Evaluation of the diagnostic accuracy of the HemoCue device for detecting anaemia in healthy school-aged children in KwaZulu-Natal, South Africa. SAfr Med J 2015;105:596-9.

31 Lu MJ, Zhong WH, Liu YX, et al. Sample Size for assessing agreement between two methods of measurement by bland-altman method. Int J Biostat 2016;12.

32 Sanchis-Gomar F, Cortell-Ballester J, Pareja-Galeano H, et al. Hemoglobin point-ofcare testing: the HemoCue system. J Lab Autom 2013;18:198-205.

33 Mukaka MM. Statistics corner: A guide to appropriate use of correlation coefficient in medical research. Malawi Med J 2012;24:69-71.
34 Lin LI. A concordance correlation coefficient to evaluate reproducibility. Biometrics 1989;45:255-68.

35 Bland JM, Altman DG. Statistical methods for assessing agreement between two methods of clinical measurement. Lancet 1986;1:307-10.

36 Paiva AA, Rondó PH, Silva SS, et al. Comparison between the HemoCue and an automated counter for measuring hemoglobin. Rev Saude Publica 2004;38:585-7.

37 Kupke IR, Kather B, Zeugner S. On the composition of capillary and venous blood serum. Clin Chim Acta 1981;112:177-85.

38 Tong E, Murphy WG, Kinsella A, et al. Capillary and venous haemoglobin levels in blood donors: a 42-month study of 36,258 paired samples. Vox Sang 2010;98:547-53.

39 Boulton FE, Nightingale MJ, Reynolds W. Improved strategy for screening prospective blood donors for anaemia. Transfus Med 1994;4:221-5.

40 Gore CJ, Scroop GC, Marker JD, et al. Plasma volume, osmolarity, total protein and electrolytes during treadmill running and cycle ergometer exercise. Eur J App/ Physiol Occup Physiol 1992;65:302-10.

41 Karakochuk CD, Rappaport Al, Barr SI, et al. Mean hemoglobin concentrations in fasting venous and non-fasting capillary blood of Cambodian women using a hemoglobinometer and an automated hematology analyzer. Clin Chem Lab Med 2017;55:e247-e50.

42 Rappaport Al, Barr SI, Green TJ, et al. Variation in haemoglobin measurement across different HemoCue devices and device operators in rural Cambodia. J Clin Pathol 2017;70:615-8.

43 von Schenck H, Falkensson M, Lundberg B. Evaluation of "HemoCue," a new device for determining hemoglobin. Clin Chem 1986;32:526-9. 